Article

\title{
Evaluating China's Paired-Assistance Policy (PAP) in Response to the Wenchuan Earthquake: A Sustainability Perspective
}

\author{
Haibo Zhang and Zhigang Tao * \\ School of Government, Center for Risk, Disaster \& Crisis Research, Nanjing University, Nanjing 210093, China; \\ zhb@nju.edu.cn \\ * Correspondence: mg1506065@smail.nju.edu.cn; Tel.: +86-025-8968-0762
}

Received: 5 September 2018; Accepted: 15 October 2018; Published: 17 October 2018

check for updates

\begin{abstract}
Taking a ten-year retrospective view, this article qualitatively evaluates the performance of the paired-assistance policy (PAP) implemented in response to China's Wenchuan earthquake from the perspective of sustainable recovery. Based on a review of relevant literature, the article proposes an integrated framework for the qualitative evaluation of the sustainability of disaster recovery. First, sustainable recovery prioritizes sustainability as the goal of activities undertaken to improve the local quality of life and local economic and environmental conditions. Second, sustainable recovery is a process involving several stages, from restoration to replacement reconstruction and finally to developmental construction. Third, sustainable recovery creates a structure that fosters local reliance through interactions between external and internal entities. Fourth, sustainable recovery emphasizes betterment over restoration and hazard mitigation. Overall, sustainable recovery integrates these four characteristics. Using the case-study method, this article qualitatively evaluates the Jiangsu-Mianzhu PAP (JM-PAP) from the perspective of sustainable recovery. The findings suggest that the JM-PAP laid a good foundation for sustainable recovery after the Wenchuan earthquake. Finally, policy recommendations are offered to improve the performance of the PAP in achieving sustainable recovery after future disasters in China.
\end{abstract}

Keywords: paired-assistance policy; Wenchuan earthquake; disaster; sustainable recovery

\section{Introduction}

The Wenchuan earthquake, which occurred at 2:28 p.m. on 12 May 2008, is one of the most severe disasters to have taken place in China since the foundation of the People's Republic of China in 1949. It registered a magnitude of 8.0 on the Richter scale, and devastated the provinces of Sichuan, Shanxi, and Gansu [1]. The earthquake caused 69,226 deaths, with 17,923 missing people, 374,643 injuries, and direct economic losses of RMB845.1 billion [1]. In addition, more than six million residences in rural areas, and 102 million square meters of dwellings in urban areas, were reported to have been severely damaged, and public infrastructure-transportation, electric power, telecommunication, water supply, and gas supply were paralyzed [1]. A large number of schools and hospitals were destroyed, and industry, agriculture, and commerce were severely affected. Large areas of forest disappeared, and other grievous damage to natural environments occurred [2]. The scale of this devastation posed enormous challenges to recovery. In response, China's central government initiated the paired-assistance policy (PAP), which assigns an economically prosperous province or province-level city to a severely affected county or county-level city to provide assistance and ultimately facilitate recovery. 
Looking back ten years later, how do we evaluate the performance of the PAP in response to the Wenchuan earthquake? Some studies have explored the effectiveness of the policy [3-6], however, the sustainability of the recovery secured by the PAP remains unclear.

To fill this gap, this article evaluates the PAP implemented in response to the Wenchuan earthquake from the perspective of sustainable recovery. Based on a review of the relevant literature, the article develops an integrated framework for qualitative evaluation of the sustainability of disaster recovery. Using the case study method, the article qualitatively evaluates the Jiangsu-Mianzhu paired-assistance policy (JM-PAP) initiated in response to the Wenchuan earthquake. The findings suggest that the JM-PAP achieved an effective recovery and laid a good foundation for long term development after the earthquake. Policy recommendations are offered to further improve PAP's performance in achieving sustainable recoveries after future disasters in China. The main contributions of this article lie in its development of an integrated framework for the qualitative evaluation of the sustainability of disaster recovery, and its evaluation of the PAP implemented to deal with the Wenchuan earthquake, from the perspective of sustainable recovery.

\section{An Integrated Framework for Evaluation of the Sustainability of Disaster Recovery}

Compared with mitigation, preparedness and response, recovery is perhaps the least explored phase of disaster management [7-13], and studies of sustainable recovery are even more scarce and dispersed $[10,11]$. In the field of public management and policy, no framework has yet been developed to evaluate the sustainability of recovery from disaster. This study constructs such a framework by integrating the findings of relevant studies.

Literally, the term "sustainable recovery" extends that of "sustainability" to post-disaster recovery. In the context of economic development, the concept of sustainability refers to the ability to meet present needs without compromising the ability of future generations to meet their needs [14] (p. 188). Disaster recovery can be regarded as short-term activities that restore vital life-support systems to minimum operating standards, and long-term activities that return life to normal [15]. The UN has proposed 17 indicators to evaluate sustainable development. Many of them are associated with economic development, quality of life, and environmental conditions [16]. In this sense, sustainable recovery entails the long-term economic development of areas affected by disasters, improvement to the quality of life of the local residents, and improvement to local environmental conditions. Building on these basic principles, sustainable recovery studies have the following four key dimensions.

First, sustainable recovery is regarded as a goal. Effective disaster recovery must be based on a trade-off between goals such as equity, efficiency, and sustainability [8]. Sustainable recovery prioritizes the goal of sustainability in recovering from a disaster. Smith [10] broadly defined two criteria for sustainable recovery: first, the post-recovery community should be a better place in which to live, work, and play than it was before the disaster; and second, the recovery should enhance the lives not only of those facing the long road to recovery, but also of future generations in the community. In a subsequent study, Smith and Wenger [11] offered three more specific criteria for sustainable recovery from disaster: (1) improving the overall quality of life of local residents; (2) enhancing the local economy; and (3), improving local environmental conditions. In this sense, sustainable recovery measures are designed to promote quality of life, economic prosperity, and environmental conditions.

In addition, sustainable recovery is regarded as a process. Nigg [17] argued that disaster recovery should be conceptualized not as an outcome of disaster, but rather as a social process that begins before a disaster occurs and encompasses decision making on the emergency response, restoration, and reconstruction activities following disaster. The first academic study of disaster recovery from this perspective was Haas, Kates, and Bowden's influential book Reconstruction Following Disaster [8,17]. The authors developed a value-added approach by characterizing post-disaster recovery as a linear process with three phases. According to this approach, the first phase is restoration, which starts in the days or weeks immediately following a disaster event. Emergency response measures, such as debris removal, the construction of temporary housing, and repairs to public services (electricity, 
water, and telecommunications), are undertaken to patch up damaged physical and social systems to make affected communities functional as quickly as possible [18]. The next phase is replacement reconstruction, which lasts for several months to a few years after a disaster. During this stage, special effort is made to enable affected communities to return to normal [18]. The final phase involves commemorative, augmentative, and developmental construction. This stage may continue for many years after a disaster and is directed toward promoting the future economic growth and long-term betterment of the locale [18]. In this sense, the process of sustainable recovery after disaster moves from restoration to replacement reconstruction and finally to commemorative, augmentative, and development construction.

Sustainable recovery is also regarded as a structure. Overall, disaster management is a complex adaptive system. Many organizations with different institutional backgrounds interact with, and adapt to, each other to collectively restore order from chaos [19-22]. Specifically, disaster recovery is an interdependent process. It requires multiple organizations with different capacities and needs to interact in response to a range of technical, social, and economic issues affecting different demographic groups to varying degrees [12]. Smith [10] defined sustainable recovery as a process undertaken by a range of stakeholders, moving beyond the basic reconstruction of a post-disaster community, region, or state. Interactions between the external organizations providing assistance and the local entities interested in long-term development foster local reliance. This is critical to the realization of a sustainable recovery.

Local reliance can be regarded as the self-reliance of individuals, organizations and communities in areas affected by disasters. Studies have suggested that local reliance can be gained through capacity building programs such as those that supplement resources, local empowerment programs that provide training and education, and local involvement in disaster recovery planning [23-25]. Local reliance is generated in three stages, from the least to the most important. The first step is to provide widespread access to a plentiful supply of the resources required for disaster recovery [26,27]. The second step is to ensure that external assistance meets local needs. Warren [28] emphasized the importance of both vertical and horizontal integration. The former increases access to resources. The latter enables governments to tailor recovery policies to the needs and capacities of the local residents. Likewise, Uphoff [29] proposed a local institutional development approach, arguing that mere compliance with, and subordination to, external organizational relief and rebuilding requirements does not produce the best results. On this matter, participatory planning for land use has been widely recognized as the best way to get local residents involved and to encourage them to express their needs [11-13,30]. The third step is to foster local reliance before and after external assistance has been withdrawn. Rubin [31] argued that sustainable recovery cannot be achieved through a top-down, inflexible, and standardized approach; local participation and initiative are essential. Mader [30] insisted that some level of local reliance on internal capacity is more effective than sole dependence on external assistance. He further asserted that communities should know what external assistance is required. Similarly, Korten [32] developed an experience-based model that balances the needs of aid recipients with the designs of aid programs and the organizational capacity of both donor and recipient institutions and groups. A recovery program is successful when it is responsive to household needs and implemented by strong organizations capable of achieving the program's goals.

Finally, sustainable recovery is regarded as an outcome. Rubin and Popkin [33] argued that the actual recovery process does not follow a predictable timeline, let alone a linear progressive sequence from response to recovery to community betterment, as assumed by the value-added approach. Instead, the real-life disaster recovery process resembles separate peaks of a mountain representing three levels of disaster recovery achievement. In this framework, named the "Rocky Mountain" model, the first peak is minimal restoration. This is the most common level, at which the physical recovery of the community is emphasized, and least attention is paid to mitigating the effects of future disasters [33]. The second peak is foresight/mitigation. Affected communities at this level engage in longer-term and more comprehensive thinking than those at the previous level. Some communities at this level 
are concerned not only with physical restoration after disaster, but also with social improvements and meeting human needs [33]. The third peak is vision/community betterment. According to Rubin and Popkin, community betterment is characterized by long-term, multiple approaches that mitigate all major hazards in the impacted areas, along with mutual aid agreements for response and recovery, multi-organization arrangements, vertical and horizontal intergovernmental relationships, improvement to emergency management capacity at the state and sub-state levels, and appropriate funding systems and operations [33]. Community betterment is needed for effective seismic safety preparedness and for the successful mitigation of damage from floods and other hazards [33]. At this level, affected communities are concerned not only with public safety but also with community betterment. This kind of disaster recovery involves the most farsighted, broad, and in-depth measures, but very few communities actually reach this level [33]. The level achieved by actual recovery depends on the joint efforts of driver and enablers [33]. In this paper, we primarily highlight the development issues related to economic growth, social processes, and environmental improvement at the community betterment level, given that disaster mitigation has already been emphasized at the previous level. Compared with the value-added approach, the Rocky Mountain model more fully acknowledges the practical contingencies involved in disaster recovery; whereas, the former describes an ideal process of disaster recovery. These two approaches are not mutually exclusive, and the latter may include the former. When sustainable recovery is regarded as an outcome, it results in vision/community betterment.

From a holistic perspective, therefore, sustainable recovery is a goal, a process, a structure, and an outcome. First, to achieve sustainable recovery, sustainability must be prioritized as a goal of recovery policy. Second, a process is designed to move from restoration to replacement reconstruction and ultimately to commemorative, augmentative, and developmental construction. Third, sustainable recovery creates a structure to foster local reliance through interactions between external organizations and local entities to meet local needs. Fourth, betterment can be achieved if the previous three strands are well-developed. These four strands are logically coherent, and their integration is feasible. Please see Figure 1.

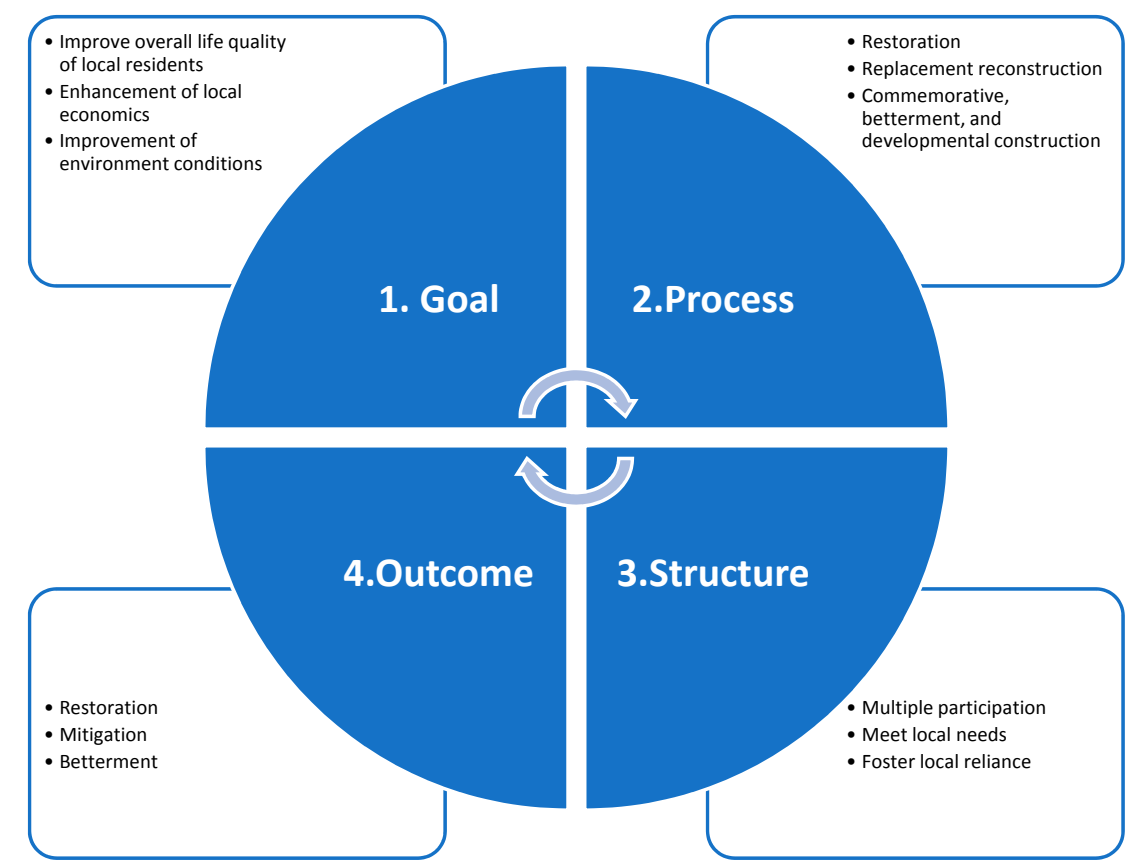

Figure 1. Integrated framework for evaluation of the sustainability of disaster recovery. 


\section{Method and Data}

\subsection{Case Study Method}

This article uses the case study method to examine the proposed framework. In the field of disaster management, case studies are the most appropriate method of ensuring that data do not perish but continue to reflect the context of disaster [34,35]. In the last decade, ever greater importance has been attached to the case study method for its advantages in helping researchers to conduct intensive studies and leverage rich materials [36-39].

The JM-PAP is selected as a case for examination of the proposed framework. This case is revelatory rather than representative $[37,40]$. Mianzhu is located in the southeast of Wenchuan county, about $30 \mathrm{~km}$ away from the epicenter of the earthquake. As a county-level city, Mianzhu consists of 21 townships, with a total population of 0.51 million. It is one of the China's most economically developed counties, ranking fourth in a 2006 comprehensive assessment of economic development in Sichuan province counties. The Wenchuan earthquake devastated Mianzhu, resulting in 11,117 casualties, 258 missing people, and 38,000 injuries. In addition, 61,000 urban homes and 133,800 rural homes were severely damaged. In other words, about 92 percent of Mianzhu's dwellings were damaged and only about 8 percent could accommodate survivors. Infrastructure, electricity facilities, telecommunication, gas supply, water supply, and drainage were all severely affected. Education and medical care systems were paralyzed. All of the city's 564 industrial enterprises were affected. Agriculture, forestry, and animal husbandry suffered huge losses. Mianzhu sustained the greatest economic damage of all affected county-level cities, with total direct economic losses reaching RMB140 billion. Jiangsu province is located in eastern China and has a population of 79.20 million. As an important pillar of the Yangtze River Economic Belt, Jiangsu is one of the provinces leading China's economic and social development. Given Jiangsu's economic strength and the huge losses suffered by Mianzhu, the province and the city were paired by the central government in its PAP. Overall, the JM-PAP encountered the greatest possible challenges to the realization of sustainable recovery in affected areas.

\subsection{Data Collection}

Most of the data were collected from semi-structured interviews and participatory observation. We organized a series of fieldwork studies to explore the process and organizational structure of the PAP. During the first fieldwork study, conducted on 7 and 8 October 2008, we sought to understand the process of restoration shortly after the earthquake. Local officials and residents were interviewed to elicit their perceptions of the PAP. Meanwhile, from September to October 2008, participatory observation was conducted in Tianyuan primary school, Deyang city, to explore the operation of social systems (schools, hospitals, and social welfare facilities) supported by the JM-PAP. The principal of Tianyuan primary school and some of its teachers and students were interviewed. We conducted the third fieldwork study on 13 November 2009, visiting Jiannan township, which had received assistance from its paired city, Nanjing, in the Jiangsu province. We interviewed local residents to collect their perceptions of the process of the PAP. The fourth fieldwork study was conducted from 8-12 August 2010. We visited the headquarters of the JM-PAP and interviewed project managers to explore the PAP's organizational structure. In addition, we visited the Mianzhu New Year Painting Base in Xiaode township, which was assisted by Suzhou city; Jiangsu-Wuxi Industrial Park in Hanwang township; and Woyun village, which was assisted by Kunshan City. We interviewed managers of the New Year Painting Base and residents of the surrounding area, managers of a factory in Jiangsu-Wuxi Industrial Park, and the head of Woyun village to explore the economic development of Mianzhu city. The fifth fieldwork study was conducted from 22-25 July 2014. We interviewed the director of Mianzhu municipal government office and managers of the above industrial park, an agricultural park, and the New Year Painting Base to investigate their operation after the JM-PAP headquarters had been dissolved. 
In addition, official reports were used to examine the outcomes of recovery; archives were used to trace the process of the JM-PAP; and statistical reports were collected and used to assess local economic growth.

\section{Results}

\subsection{Case Summary}

The basic principle of the PAP was that "one province assists one severely devastated county." China's State Council appointed 20 economically prosperous provinces and province-level cities to assist 20 severely affected counties or county-level cities in Sichuan, Gansu, and Shanxi [41]. The provinces/cities and counties/cities were paired on the basis of the former's economic capacity to provide assistance, and the damage sustained by the latter, with consideration of the paired relationships formed during the relief phase. China's State Council required each assisting province or city to provide annual aid amounting to no less than $1 \%$ of its fiscal revenue for the three years of the PAP period (see Table 1).

Table 1. Assisting and assisted parties under the paired-assistance policy (PAP).

\begin{tabular}{|c|c|c|c|}
\hline & $\begin{array}{c}\text { Assisting } \\
\text { Provinces/Cities }\end{array}$ & Assisted Counties/Cities & $\begin{array}{l}\text { Damage Assessment of } \\
\text { Assisted Counties/Cities }\end{array}$ \\
\hline 1 & Guangdong & Wenchuan county, Sichuan & Extremely severe \\
\hline 2 & Jiangsu & Mianzhu city, Sichuan & Extremely severe \\
\hline 3 & Shanghai & Dujiangyan city, Sichuan & Extremely severe \\
\hline 4 & Shandong & Beichuan county, Sichuan & Extremely severe \\
\hline 5 & Zhejiang & Qingchuan county, Sichuan & Extremely severe \\
\hline 6 & Beijing & Shifang city, Sichuan & Extremely severe \\
\hline 7 & Fujian & Penzhou city, Sichuan & Extremely severe \\
\hline 8 & Tianjin & Ningqiang county, Lveyang county, Shanxi & Severe \\
\hline 9 & Liaoning & Anxian county, Sichuan & Extremely severe \\
\hline 10 & Anhui & Songpan county, Sichuan & Severe \\
\hline 11 & Henan & Jiangyou city, Sichuan & Severe \\
\hline 12 & Hebei & Pingwu county, Sichuan & Extremely severe \\
\hline 13 & Chongqing & Congzhou city, Sichuan & Severe \\
\hline 14 & Shenzhen & $\begin{array}{l}\text { Wen county, Wudu district, Kang county, } \\
\text { and Zhouqu county, Gansu }\end{array}$ & Severe \\
\hline 15 & Jilin & Heishui county, Sichuan & Severe \\
\hline 16 & Hunan & Lixian county, Sichuan & Severe \\
\hline 17 & Shanxi & Maoxian county, Sichuan & Extremely severe \\
\hline 18 & Hubei & Hanyuan county, Sichuan & Severe \\
\hline 19 & Heilongjiang & Jiange county, Sichuan & Severe \\
\hline 20 & Jiangxi & Xiaojin county, Sichuan & Severe \\
\hline
\end{tabular}

Notes: (1) Pairs were determined based on the economic capacity of the assisting parties and the damage sustained by the assisted parties, with consideration of paired relationships formed during the earlier relief phase. (2) Damage assessments are as given in a report by the China National Disaster Reduction Committee. Overall, 10 areas were extremely severely damaged, 41 were severely damaged, and 186 were damaged. The 10 extremely severely damaged areas reported 97.2 percent of the region's casualties and missing people, 42.9 percent of its collapsed buildings, and 39.5 percent of its direct economic losses. (3) Expected financial aid is given as total input over three years based on appropriate temporal standardization.

On 20 June 2008, to implement the PAP set out by the State Council, Liang Baohua, secretary of Jiangsu's provincial party committee, and Luo Zhijun, Governor of Jiangsu Provincial Government, visited Mianzhu to connect the two parties, and made the decision that each township in the affected area would be assisted by one city in Jiangsu. Accordingly, 13 municipal-level cities and 8 county-level cities in Jiangsu were paired with Mianzhu's 21 severely affected townships (see Table 2). 
Table 2. Assisting and assisted parties under the Jiangsu-Mianzhu paired-assistance policy (JM-PAP).

\begin{tabular}{cccc}
\hline Assisting Cities & Assisted Townships & Assisting Cities & Assisted Townships \\
\hline Suzhou city & Xiaode township & Yancheng city & Xinan township \\
Wuxi city & Hanwang township & Xuzhou city & Fuxing township \\
Changzhou city & Zundao township & Zhangjiagang city & Dongbei township \\
Zhenjiang city & Banqiao township & Changshu city & Tumen township \\
Nanjing city & Jiannan township & Kunshan city & Guangji township \\
Yangzhou city & Jiulong township & Taicang city & Qitian township \\
Taizhou city & Gongxing township & Wujiang city & Xinglong township \\
Suqian city & Mianyuan township & Jiangyin city & Qingping township \\
Huaian city & Yuquan township & Wujin city & Jinhua township \\
Lianyugang city & Shidi township & Yixing city & Tianping township \\
Nantong city & Xinshi township & & \\
\hline
\end{tabular}

Note: Pairs were determined based on the economic capacity of the assisting parties and the damage sustained by the assisted parties, with consideration of the paired relationships formed during the earlier relief phase.

\subsection{Sustainable Recovery as a Goal of the JM-PAP}

China's central government prioritized sustainability as the goal of recovery efforts following the Wenchuan earthquake. On 8 June 2008, the "Regulations on Post-Wenchuan Earthquake Recovery" (RPWER), the first regulations formulated for disaster recovery in China, were approved to legislate policies related to the recovery. On 19 September 2008, under the RPWER, the Post-Wenchuan Earthquake Recovery Master Plan (PWERMP) was developed by the State Council to implement the recovery efforts.

The PWERMP was based on eight main principles. First, people and their livelihoods should be prioritized in the recovery process. Housing, public service facilities and infrastructure, and employment should also be emphasized. Second, scientific planning should be adopted to reduce potential hazards and threats. Third, the disaster recovery measures should be integrated with China's "Western Development Strategy" to promote the industrialization, urbanization, and rural development of affected areas. Fourth, the recovery should rely on collaboration between governments, the private sector, social organizations, and local residents. Fifth, safety should be ensured, and a strict commitment should be made to meeting earthquake resistance building standards. Sixth, the recovery measures should save resources, protect cultivated lands, and leverage original facilities to the greatest possible extent. Seventh, traditional culture should be maintained, and reconstruction should not affect historical landmarks, common property, or traditional counties. Eighth, the recovery measures should be tailored to the local situation and implemented step by step to uphold local economic, social, cultural, natural, and ethnic diversity.

The PWERMP stipulated that under the PAP, three years would be required to accomplish the major goal of recovery, ensuring that basic livelihoods and social and economic development had returned to, or exceeded, pre-disaster levels and providing a foundation for future sustainable development. This overall goal had six components: First, to provide every family with a dwelling; second, to ensure that at least one member of every family had a permanent job, and that both the per capita disposable income of urban residents and the net per capita income of rural residents exceeded pre-disaster levels; third, to provide all people in the affected areas with social security cover and access to compulsory education, public health services, and public cultural and sports services; fourth, to restore transportation, telecommunication, energy and water supply infrastructure to pre-disaster levels or higher; fifth, to develop the economy by cultivating promising local industries and, optimizing industry structure and spatial layout; and sixth, to improve ecological environments and significantly increase disaster resistance capacity.

All six components were well-implemented during the process of JM-PAP. Below is an excerpt from an interview with a local officer: 
"Some urban residents got well-paid jobs in the Hanwang Industrial Park. Rural residents were taught to plant grapes or strawberries, and their income doubled over the last decade. Before the Wenchuan earthquake, this county ranked fourth in a comprehensive assessment of the economic development of counties of Sichuan province. However, owing to the severe damage caused by the Wenchuan Earthquake, its ranking dropped to 34th. With assistance from Jiangsu, the economy boomed and was enhanced, ranking 19th in a comprehensive assessment. We believed that our ranking would come back to the top ten in this year. Meanwhile, many trees were planted to improve the local environmental condition." Overall, the goal of the Wenchuan earthquake recovery initiative fully met the criteria for sustainable recovery. To achieve this goal, the JM-PAP was required to promote the quality of life of local residents, enhance the local economy, and improve local environmental conditions.

\subsection{Sustainable Recovery as a Process under the JM-PAP}

The process of recovery supported by the JM-PAP was divided into three stages. The first stage involved restoration, starting with the construction of temporary housing in the emergency response phase immediately after the earthquake. Jiangsu province was appointed by the central government to contribute to emergency response operations in Mianzhu, such as search and rescue, relief, and the construction of temporary housing, before the initiation of the PAP. A total of 12,966 search and rescue personnel were sent to Mianzhu from Jiangsu [42]. On the site of the current SuMian Garden, personnel from Jiangsu province built 28,000 prefabricated houses, the world's largest collection of temporary shelters, which accommodated tens of thousands of local residents [42].

The second stage involved replacement reconstruction to enable the affected communities to return to normal. The reconstruction projects were divided into two types. The first were "turn-key" mode projects, in which Jiangsu personnel were responsible for planning and reconstruction and transferred responsibility for the projects to Mianzhu only once reconstruction was complete. The second were "pay-check" mode projects, for which Jiangsu provided only financial support and Mianzhu was responsible for planning and reconstruction. The mode selection depended on negotiation between the paired parties.

The third stage entailed developmental construction to ensure the long-term sustainability of recovery. As soon as most of the replacement reconstruction had been completed, the construction of industrial parks began. By 12 May 2011, 11 paired-cooperation industrial parks and 24 agricultural parks had been constructed $[43,44]$. An industrial park is a tract of land developed and subdivided into plots according to a comprehensive plan, with provision for roads, transport and public utilities to be used by groups of industries [45]. It is characterized by clusters of compatible organizations and industries within one location, thereby reducing the cost of infrastructure, utilities, and services [46]. For example, in the Suzhou Industrial Park, a benchmark industrial park in Jiangsu Province, companies specializing in biological medicine and artificial intelligence share infrastructure with research institutions and universities and are mutually supported [47]. Jiangsu has taken this model and transplanted it to industrial parks in Mianzhu.

Mianzhu's relatively strong industrial base allowed two industrial parks to be constructed under the JM-PAP (see Table 3). In addition, to ensure the long-term sustainability of Mianzhu's agriculture and handicraft industries, the Jiangsu High Efficiency Agriculture Park and Mianzhu New Year Painting Base, respectively, were constructed. These industrial and agricultural parks and the handicraft base offered more than 20,000 jobs to local residents [48]. After Jiangsu's recovery assistance had been withdrawn, a broader scope of economic and social cooperation was established. On 21 September 2010, Jiangsu and Sichuan signed the "Jiangsu-Sichuan Strategic Cooperation Agreements for Economic and Social Development" to foster long-term cooperation between the regions [49]. 
Table 3. Paired-cooperation industrial parks.

\begin{tabular}{ccc}
\hline Name & $\begin{array}{c}\text { Assisting } \\
\text { Provinces/Cities }\end{array}$ & $\begin{array}{c}\text { Assisted } \\
\text { Counties/Cities }\end{array}$ \\
\hline Dujiangyan-Zhangjiang Science and Technology Park & Shanghai & Dujiangyan city \\
\hline Beichuang-Shandong Cooperative Industrial Park & Shandong & Beichuan county \\
\hline Anxian-Liaoning Cooperative Industrial Park & Liaoning & Anxian county \\
\hline Jiangyou-Henan Cooperative Industrial Park & Henan & Jiangyou city \\
\hline Qingchuan-Chuanzhe Cooperative Industrial Park & Zhejiang & Qingchuan county \\
\hline Jianmen-Chuanhei Cooperative Industrial Park & Heilong Jiang & Jiange county \\
\hline Mianzhu-Jiangsu Industrial Park & Jiangsu & Mianzhu city \\
\hline Hanwang-Wuxi Industrial Park & Jiangsu & Mianzhu city \\
\hline Shifang-Beijing Industrial Park & Beijing & Shifang city \\
\hline Penzhou-Chuanmin Industrial Park & Fujian & Pengzhou city \\
\hline Pingwu-Hebei Industrial Park & Hebei & Pingwu county \\
\hline Data source: Ministry of Information and Technology of the PRC. &
\end{tabular}

\subsection{Sustainable Recovery as a Structure under the JM-PAP}

Multiple participating organizations with different institutional backgrounds provided the numerous resources required to support Mianzhu's recovery. Governmental agencies played the leading role in restoration and replacement reconstruction. On 7 August 2008, the headquarters of the JM-PAP were established and began to operate in Mianzhu. The first 22 officials were experts from the departments of construction, transportation, water resources, public health, education, civil affairs, finance, commerce, social security, and public security in Jiangsu, with an average age of 39.5 years. They were selected on the basis of governmental mobilization, voluntary participation, and departmental approval. Mr. Liang Xuezhong, Vice Secretary-General of Jiangsu Provincial Government, was appointed as the director. Twenty branches of the JM-PAP's headquarters were established, and 200 officials from Jiangsu worked in Mianzhu for three years. In addition, state-owned companies and private firms played a leading role in developmental construction. As of December 2017, 111 state-owned companies and private firms had signed agreements with Mianzhu city, representing an international investment of RMB11.9 billion. Nineteen enterprises from Jiangsu invested more than RMB3 billion in Mianzhu [50]. During this process, relationships were established for mutual benefit. For example, to establish Wuxi-Hanwang Industrial Park, more than 120 state-owned companies and private firms in the food, textile, and garment industries were mobilized to visit Mianzhu. However, none of these enterprises agreed to invest in the park, because the logistics costs involved in exporting their products from Mianzhu to other countries would have been too high. They preferred to donate rather than accept the risk of failure and damage to their reputation. After intensive investigation, the JM-PAP's subsidiary headquarters in the Hanwang township identified Deyang's advantage in heavy equipment manufacturing. In June 2009, 30 companies in high-technology industries visited Wuxi-Hanwang Industrial Park, and seven decided to sign investment contracts allowing them to remain there. Third, public institutions and nonprofit organizations played a leading role in restoration and replacement reconstruction. More than 110 teachers and 600 medical personnel from Jiangsu stayed in Mianzhu to restore the proper operation of schools and hospitals [50]. In addition, nonprofit organizations played a complementary role in meeting individual needs. For example, the Amity Foundation invited engineers from Hong Kong to teach local residents how to build earthquake-resistant dwellings, provided containers for grain storage, and reorganized local art performance teams to inspire local residents. More than 1000 officials and professionals and 100,000 construction workers from Jiangsu contributed to the JM-PAP [50]. 
Local reliance was fostered in different ways, but primarily through capacity building programs. These were initiated by local individuals or organizations that had access to plentiful external resources. For example, during the JM-PAP, Jiangsu invested RMB11 billion to initiate 295 projects in Mianzu [48]. Schools and hospitals were built, local infrastructure such as roads and bridges was restored or strengthened, and local residents were resettled in new dwellings and offered well-paying jobs. All of these policies were adopted to improve the capacities of the local residents and organizations.

Local reliance was also fostered through a large number of training programs. During the three years covered by the PAP, 28 local officials from Mianzhu were selected for training in the business operation of industrial parks in Jiangsu at provincial level or above, teaching them how to manage industrial parks. Another 10 officials from Mianzhu were positioned in township governments to learn how to promote economic development at township level. Three hundred and fifty Mianzhu officials were selected for training in Jiangsu to improve their skills in industrial development, new rural construction, public administration, and community affairs. Importance was also attached to the capacity of local residents: more than 100 agricultural technical staff and 300 villagers were trained by agricultural experts from Jiangsu; more than 400 school principals, teachers, and medical personnel were trained in Jiangsu; and about 3800 medical personnel were trained by Jiangsu personnel in Mianzhu [50]. This process improved the self-reliance of local residents through the transference of ideas, insights, knowledge, skills, and experiences from Jiangsu officials to local residents and officials in Mianzhu.

Many examples illustrating the growth of local reliance can be found by tracing the changes over the past ten years. First, essential local industries were developed. For example, before 2008, Mianzu's industries were highly dispersed, resource consuming, and environmentally contaminating. After implementing the JM-PAP, to some extent, these industries became centralized, resource saving, and environmentally friendly. In addition, the local officials and residents gained the skills and experience required to operate the industrial and technology parks. Another example is the huge progress in tourism development. In 2017, more than five million tourists visited Mianzu, and income from local tourism reached RMB5 billion, representing increases of 5.8 times and 15.2 times respectively, compared to 2008 [51]. Second, local agriculture was significantly improved. For example, in explaining how Jiangsu helped Mianzu operate the agricultural parks, the local authorities recalled that, "various kinds of strawberries and grapes were introduced from Jiangsu to Mianzu, and experts from Jiangsu gave us their phone numbers to let us call them directly if we needed help." A local rural resident said that, "I was taught how to plant strawberries and grapes, and my annual income increased to RMB40,000 per year because of these crops. In 2008, the figure was just RMB8000 per year." Third, local cultural heritage was protected and promoted. For example, Mianzu was famous for its Block-printed Chinese New Year Pictures, a Chinese intangible cultural heritage skill with more than 1000 years of history. However, this intangible cultural heritage skill nearly disappeared due to the severe damage caused by the earthquake. In the disaster recovery process, the local government provided financial and policy support to promote local studios and individual inheritors. In the Xiaode village alone, more than 1000 local residents made their living by handcrafting the Mianzu Block-printed Chinese New Year Pictures [52]. More than 30,000 prints were exported to other countries and local residents' income increased to RMB20,000 per year [52]. Further, more than 700,000 tourists visited Xiaode and local tourism income reached RMB18 million in 2017 [52]. Protection and promotion of this cultural heritage skill even reduced the severe poverty of the local residents.

Notwithstanding the achievements, local reliance was, admittedly, insufficient overall. First, about $90 \%$ of the replacement reconstruction consisted of "turn-key" projects, in which local residents had no opportunity to participate. Second, although the PAP covered three years, its objectives were expected to be accomplished within two years. As a result, the time available for land-use planning was limited. For example, all of the land-use planning maps formulated for Mianzhu's recovery were prepared in Jiangsu and delivered to Mianzhu by air [50]. Third, even though most local needs were 
met due to the tremendous assistance provided by Jiangsu, the local residents had few chances to become involved.

\subsection{Sustainable Recovery as an Outcome under the JM-PAP}

Ten years after the earthquake, recovery has gone beyond restoration and mitigation to reach the level of betterment. Jiangsu invested RMB11.28 billion in 295 restoration projects, comprising 265 "turn-key" projects and 30 "pay-check" projects. Financial support amounting to RMB8.62 billion was allocated to housing reconstruction, and a further RMB3.021 billion was used to reconstruct schools, hospitals, and other public service facilities to high standards. Overall, 64 schools, 29 hospitals, 41 cultural and civil facilities, 139,600 rural dwellings, 12,600 urban dwellings, 138 roads, bridges, and water resources, and more than $1000 \mathrm{~km}$ of urban and rural roads were reconstructed [48].

In terms of hazard mitigation, the affected areas were classified into three types. First were areas considered at a relatively low risk, in which reconstruction could take place in the original locations and a large population and numerous industries could be accommodated. Second were areas at risk, where only moderate recovery was possible and only a small population could be housed. Third were areas at high risk, in which only ecological recovery measures to repair and protect the environment could take place [1] (see Table 4). The JM-PAP was supported by this regulation.

Table 4. Three types of recovery post-Wenchuan earthquake.

\begin{tabular}{ccccc}
\hline Types & Areas Included (sq.km) & Proportion (\%) & Population (million) & Proportion (\%) \\
\hline Recovery & 10,077 & 7.6 & 772.8 & 38.9 \\
Moderate recovery & 38,320 & 28.9 & 1180.1 & 59.4 \\
Ecological recovery & 84,199 & 63.5 & 33.8 & 1.7 \\
\hline
\end{tabular}

To mitigate future hazards, a series of policies was adopted at the provincial level in Sichuan. First, all new construction, particularly schools and hospitals, was required to meet higher earthquake resistance standards (a magnitude of 8.0 on the Richter scale) [53]. Second, engineering measures and relocation policies were adopted to reduce seismic risk. By 24 February 2012, residents had been relocated from 2334 places at seismic risk [43], and the remaining such places were well- managed by the end of 2015 [54,55]. More than 700,000 local residents were relocated [56]. Third, comprehensive land-use plans were formulated for reconstruction in rural areas. In Mianzhu, 120 urban and rural planners from Jiangsu conducted an extensive land-use investigation lasting for more than 50 days, based on which they developed overall and affiliated plans over a 50-year horizon [57].

In terms of betterment, local officials said that after the recovery measures, Mianzhu's buildings, infrastructure, and public facilities were at least 20 years more advanced than they had been prior to the earthquake. In terms of local economic development, growth in the local gross domestic product (GDP) and the increased income of the local residents have been the most meaningful indicators of betterment emanating from the disaster recovery. Figures 2 and 3 both demonstrate that significant economic development has been achieved in Mianzhu. In this sense, Mianzhu has reached the highest level of recovery, which is attained by very few disaster-affected communities.

Figure 3 also shows significant improvement to the quality of life of the local residents resulting from their increased income. In addition, a series of policies was adopted to improve the residents' quality of life. For example, schools and hospitals were built and teachers and doctors in Mianzu were trained by their counterparts in Jiangsu. Thus, children and other citizens received better education and medical care [50]. New dwellings were also required to meet a higher earthquake resistance standard, making them safer. Roads and bridges were built, so the local rural residents' transportation became more convenient. Thus, the quality of life of local residents was greatly improved.

Finally, environmental and ecological conditions were prioritized. For example, the new Hanwang village was surrounded by 250,000 square meters of parkland. In addition, 102 eco-villages, 5 eco-communities, and 17 eco-schools were built [50]. The total forest coverage rate in Mianzu, 
increased to $51.9 \%$, higher than the percentage before the disaster. To a large extent, Mianzhu achieved a sustainable recovery in terms of its environmental conditions. Overall, the disaster recovery efforts resulted in the betterment of the community, characterized by the enhancement of the local economy, improvement to the quality of life of the local residents, and promotion of local environmental conditions.

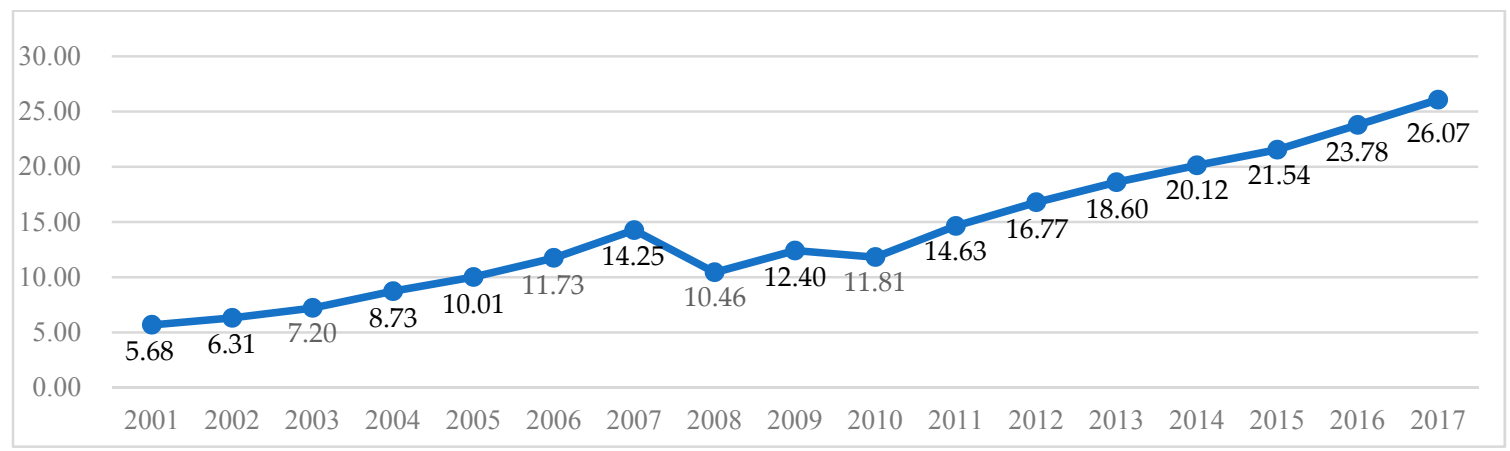

Figure 2. Local GDP growth in Mianzhu from 2001 to 2017. Note. Figures given in RMB billion. Data source: Mianzhu Statistics Annual Report (2002-2018).

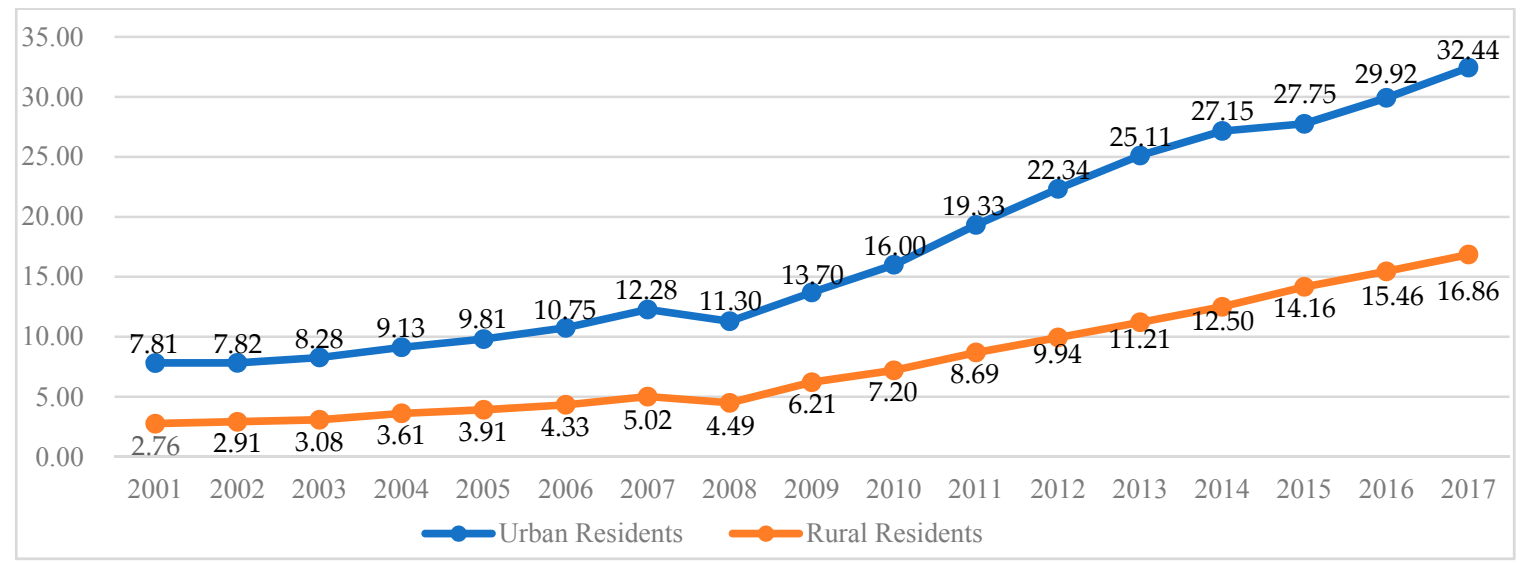

Figure 3. Growth in income of Mianzhu residents from 2001 to 2017. Note. Figures given in RMB1000. Data source: Mianzhu Statistics Annual Report (2002-2018).

\section{Conclusions}

Overall, the outcomes of the JM-PAP showed that China's PAP could achieve an effective recovery and lay a good foundation for long-term development following the Wenchuan earthquake [4-6]. The achievement of sustainable recovery by the JM-PAP relied on the collective performance of four factors.

First, the JM-PAP prioritized sustainability as the goal of recovery efforts. Among the objectives of the JM-PAP under the PWERMP were promoting the quality of life of local residents, enhancing the local economy, and improving environmental conditions [11]. These are all conditions for the achievement of sustainable recovery after disaster. As a focal national event, a disaster has a high issue salience and receives considerable media attention, and its aftermath facilitates policy learning [58]. The Wenchuan earthquake was the most severe disaster in China in recent decades, with a very high issue salience and considerable media attention, and its aftermath facilitated policy learning to achieve comprehensive betterment through the incorporation of disaster recovery into China's Western Development Strategy. In this sense, the more catastrophic a disaster, the more likely sustainability is to be prioritized in disaster recovery. A disaster at community level is less likely to elicit an emphasis on sustainable recovery. 
Second, the JM-PAP defined a long-term process moving from restoration to replacement reconstruction to developmental construction. Restoration started immediately after the disaster through the assistance of Jiangsu province, mainly involving search and rescue, relief, and the construction of temporary housing. During the replacement reconstruction stage, urban and rural dwellings and roads, transportation and water supply infrastructure, schools, and hospitals were reconstructed to enable the affected communities to return to normal. Subsequently, to achieve long-term sustainability, developmental construction was initiated. Supported by the JM-PAP, industrial and agricultural parks and a handicraft base were established to revitalize the local economy. Jiangsu and Sichuan entered into mutually beneficial cooperation to foster the long-term development of the new industrial and agricultural parks and handicraft base. Sustainable recovery is progressive [33], and recovery following a more catastrophic disaster is also more likely to be progressive [59].

Third, the JM-PAP created a network structure that accommodated the participation of multiple organizations and fostered local reliance through the interaction of external entities and local officials and residents. Governmental agencies and public institutions played the leading roles, complemented by nonprofit organizations, in restoration and replacement reconstruction, and state-owned companies and private firms contributed to developmental construction. Together, they provided the numerous resources required to support Mianzhu's recovery. Local reliance was fostered by the establishment of a wide range of training programs for local residents, officials, enterprise managers, school principals and teachers, and medical personnel. New ideas, knowledge, skills, and experiences were gained from daily interactions with external entities. However, local involvement was insufficient, because most restoration and replacement reconstruction projects were undertaken by external entities. Thus, the local residents had few opportunities to contribute to land-use planning, given that most physical reconstruction was completed in the "turn-key" mode. Overall, the implementation and outcomes of the JM-PAP show that sustainable recovery can be achieved only through a flexible structure, even in the centralized context of China [12,13,28,30,32].

Fourth, the JM-PAP realized its goal of betterment. Restoration and mitigation were amply achieved. Urban and rural dwellings, transportation and water supply infrastructure, schools, hospitals, and social welfare facilities were all reconstructed to high standards. All construction was required to meet an earthquake resistance standard of 8.0 on the Richter scale, and seismic hazards were identified and managed. Land-use planning was conducted in rural areas. The affected areas were classified into three types, recovery, moderate recovery, and ecological recovery, and those living in the high-risk ecological recovery areas were relocated. A thriving local economy developed in Mianzhu. Local GDP and residents' income showed continuous growth in the aftermath of the Wenchuan earthquake. This betterment was produced by the joint efforts of drivers and enablers [17]; or, in terms of the framework proposed here, the effective integration of goals, process, and structure.

Given the capacity of the PAP to realize both effective and sustainable recovery, this policy should be widely used in future disaster recovery contexts. From the perspective of sustainable recovery, the PAP can be refined in four ways. First, more local involvement is to be encouraged, even during the restoration phase. Second, land-use planning needs to encourage and accommodate local involvement. Third, greater importance needs to be attached to fostering local reliance through training programs. Fourth, the PAP should be implemented with a flexible timeframe rather than limited to two or three years.

In future studies, a framework for the quantitative evaluation of the sustainability of recovery should be developed.

Author Contributions: H.Z. constructed the survey, developed the theoretical framework and wrote the first draft of this paper. Z.T. contributed to materials and editing. Both authors reviewed the final draft of the article before submission.

Funding: This research was funded by the China Social Science Foundation (grant number 13AGL009). 
Acknowledgments: We gratefully thank to Simona Perry's and Ziqiang Han's suggestion and comments in writing and revising the article.

Conflicts of Interest: The authors declare no conflicts of interest.

\section{References}

1. The State Council of the PRC. Post-Wenchuan Earthquake Restoration and Reconstruction Master Plan. 2008. Available online: http://www.gov.cn/zhengce/content/2008-09/24/content_6121.htm (accessed on 15 August 2018). (In Chinese)

2. Zhang, H.B. What has China Learnt from Disasters? Evolution of the Emergency Management System after SARS, Southern Snowstorm, and Wenchuan Earthquake. J. Comp. Policy Anal. 2012, 14, 234-244. [CrossRef]

3. Zhong, K.B. Counter-Partner Assistance Program in Disaster Reconstruction: Origin and Development. Comp. Econ. Soc. Syst. 2011, 6, 140-146. (In Chinese)

4. Zhong, K.B. Explaining the Mechanism of the Paired Assistance to Disaster-Affected Areas Program Work in China: A Multiple Moderated-Competition Framework. J. Gansu Adm. Inst. 2018, 1, 4-14, 126. (In Chinese)

5. Zhong, K.B.; Lu, X.L. Exploring the Administrative Mechanism of China's Paired Assistance to Disaster Affected Areas Programme. Disasters 2018, 42, 590-612. [CrossRef] [PubMed]

6. Zhang, H.B.; Zhai, J. Multiple Participation, Horizontal Integration and Urban-Rural Intersection: The Mechanism of Chinese Paired-Assistance of Policy Contributing to the Sustainable Recovery of the Wenchuan Earthquake. In Proceedings of the International Conference on Disaster Governance in Asia, National University of Singapore, Singapore, 7-8 November 2013.

7. Rubin, C.B. Recovery from Disaster. In Emergency Management: Principles and Practices for Local Government; Drabek, T., Hoetmer, G., Eds.; International City Management Association: Washington, DC, USA, 1991; ISBN 0873260821.

8. Berke, P.R.; Kartez, J.; Wenger, D. Recovery after Disaster: Achieving Sustainable Development, Mitigation and Equity. Disasters 1993, 17, 93-109. [CrossRef] [PubMed]

9. Quarantelli, E.L. The Disaster Recovery Process: What We Know and Do Not Know from Research; Preliminary Paper \#286; Disaster Research Center at the University of Delaware: Newark, DE, USA, 1999.

10. Smith, G.P. Holistic Disaster Recovery: Creating a More Sustainable Future. FEMA Training Course, US, 2004. Available online: http:/ / training.fema.gov/EMIWeb/edu/sdr.asp (accessed on 7 December 2013).

11. Smith, G.P.; Wenger, D. Sustainable Recovery: Operationalizing an Existing Agenda. In Handbook of Disaster Research; Rodríguez, H., Quarantelli, E.L., Dynes, R.R., Eds.; Springer: New York, NY, USA, 2007; pp. 234-257, ISBN 978-0-387-73952-6.

12. Comfort, L.K.; Birkland, T.A.; Cigler, B.A.; Nance, E. Retrospectives and Prospective on Hurricane Katrina: Five Years and Counting. Public Adm. Rev. 2010, 70, 669-678. [CrossRef]

13. Smith, G.P. Planning for Post-Disaster Recovery: A Review of the United States Disaster Assistance Framework; Public Entity Risk Institute: Virginia, VA, USA, 2011.

14. United Nations. The World Commission on Environment and Development, 1987. Available online: http:/ / www.un-documents.net/wced-ocf.htm (accessed on 15 May 2018).

15. Mcloughlin, D. A Framework for Integrated Emergency Management. Public Adm. Rev. 1985, 45, 165-172. [CrossRef]

16. United Nation Development Programme. Sustainable Development Goals, 2018. Available online: http:/ / www.undp.org/content/undp/en/home/sustainable-development-goals.html (accessed on 25 September 2018).

17. Nigg, J.M. Disaster Recovery as a Social Process; Preliminary Paper \#219; Disaster Research Center at the University of Delaware: Newark, DE, USA, 1995.

18. Haas, J.E.; Kates, R.W.; Bowden, M.J. Reconstruction Following Disaster; The MIT Press: Cambridge, MA, USA, 1977.

19. Comfort, L.K. Shared Risk: Complex Systems in Seismic Response; Pergamon Press: New York, NY, USA, 1999; ISBN 0080432115.

20. Comfort, L.K. Rethinking Security: Organizational Fragility in Extreme Events. Public Adm. Rev. 2002, 62, 98-107. [CrossRef] 
21. Comfort, L.K.; Kapucu, N. Interorganizational Coordination in Extreme Events: The World Trade Center Attacks, September 11, 2001. Nat. Hazards 2006, 39, 309-327. [CrossRef]

22. Zhang, H.B.; Zhang, X.S.; Comfort, L.K.; Chen, M. The Emergence of an Adaptive Response Network: The April 20, 2013 Lushan, China Earthquake. Saf. Sci. 2016, 90, 14-23. [CrossRef]

23. Olson, R.S. Towards a Politics of Disaster: Losses, Values, Agendas, and Blame. Int. J. Mass Emerg. Disasters 2000, 18, 265-287.

24. Garnett, J.D.; Moore, M. Enhancing Disaster Recovery: Lessons from Exemplary International Disaster Management Practices. J. Homel. Secur. Emerg. Manag. 2010, 7, 1271-1283. [CrossRef]

25. Binder, S.B.; Baker, C.K. Culture, local capacity, and outside aid: A community perspective on disaster response after the 2009 tsunami in American Sāmoa. Disasters 2016, 41, 282-305. [CrossRef] [PubMed]

26. Tierney, K.; Trainor, J. Networks and Resilience in the World Trade Center Disaster; Working Paper; Disaster Research Center at the University of Delaware: Newark, DE, USA, 2003.

27. Waugh, W.L., Jr.; Streib, G. Collaboration and Leadership for Effective Emergency Management. Public Adm. Rev. 2006, 66, 131-140. [CrossRef]

28. Warren, R. The Community in America; University Press of America: Washington, DC, USA, 1987; ISBN 0819154946.

29. Uphoff, N. Local Institutional Development: An Analytical Sourcebook with Cases; Kumarian Press: West Hartford, CT, USA, 1986; ISBN 0-931816-45-9.

30. Mader, G.; Spangle, W.E.; Blair, M.L. Land Use Planning after Earthquakes; W. Spangle and Associates: Menlo Park, CA, USA, 1980.

31. Rubin, C.B.; Saperstein, M.D.; Barbee, D.G. Community Recovery from a Major Natural Disaster; Program on Environment \& Behavior Monograph; Louis de la Parte Florida Mental Health Institute (FMHI), University of South Florida: Tampa, FL, USA, 1985.

32. Korten, D.C. Community Organization and Rural Development: A Learning Process Approach. Public Adm. Rev. 1980, 40, 480-511. [CrossRef]

33. Rubin, C.B.; Popkin, R. Disaster Recovery after Hurricane Hugo in South Carolina; Working Paper \#39; Natural Hazards Research and Applications Information Center, University of Colorado Boulder: Boulder, CO, USA, 1990.

34. Rodríguez, H.; Quarantelli, E.L.; Dynes, R.R. Handbook of Disaster Research; Springer: New York, NY, USA, 2007; ISBN 978-0-387-73952-6.

35. Zhang, H.B.; Tong, X. Structural Change in China's Emergency Management: Theoretical Generalizations. Soc. Sci. China 2016, 2, 77-98.

36. Gerring, J. What Is a Case Study and What Is It Good For? Am. Polit. Sci. Rev. 2004, 98, 341-354. [CrossRef]

37. Eisenhardt, K.M.; Graebner, M.E. Theory Building from Cases: Opportunities and Challenges. Acad. Manag. J. 2007, 50, 25-32. [CrossRef]

38. Gibbert, M.; Ruigrok, W.; Wicki, B. What Passes as a Rigorous Case Study? Strat. Manag. J. 2008, 29, 1465-1474. [CrossRef]

39. Yin, R.K. Case Study Research: Design and Methods; Sage: Los Angeles, CA, USA, 2013; pp. 4-5, ISBN 978-1-4522-4256-9.

40. Yin, R.K. The Case Study Crisis: Some Answers. Adm. Sci. Q. 1981, 26, 58-65. [CrossRef]

41. The State Council of the PRC. Recovery of the Wenchuan Earthquake and the Paired-Assistance Policy. 2008. Available online: http://www.gov.cn/zwgk/2008-06/18/content_1019966.htm (accessed on 15 August 2018). (In Chinese)

42. Net Base News. Jiangsu's and Mianzu Paired-Assistance Have Were Finished within Two Years. 2010. Available online: http:/ / news.163.com/10/0510/06/66A8DVHQ00014AED.html (accessed on 20 May 2013). (In Chinese)

43. Ministry of Information and Technology of the PRC. Three Years after the Wenchuan Earthquake, Sichuan's Industrial Recovery and Reconstruction Have Achieved a Great Success. 2011. Available online: http:// www.miit.gov.cn/n1146290/n1146397/c4246880/content.html (accessed on 7 November 2013). (In Chinese)

44. Ministry of Agriculture of the PRC. Policy Review of Assistance Provided by Chinese Ministry of Agriculture for the Agricultural Recovery of Sichuan Province after the Wenchuan Earthquake. 2011. Available online: http:/ /jiuban.moa.gov.cn/fwllm/jrsn/201105/t20110512_1991855.htm (accessed on 7 November 2013). (In Chinese) 
45. United Nations Industrial Development Organization (UNIDO). Industrial Estates: Principles and Practices; UNIDO: Vienna, Austria, 1997.

46. Geng, Y.; Zhao, H. Industrial park management in the Chinese environment. J. Clean. Prod. 2009, 17, 1289-1294. [CrossRef]

47. Suzhou Industrial Park. An Introduction to the Suzhou Industrial Park. 2018. Available online: http:/ / www. sipac.gov.cn/zjyq/yqgk/201801/t20180120_677084.htm (accessed on 25 September 2018). (In Chinese)

48. Sichuan News. Jiangsu Invested RMB11 Billion to Jiangsu and Mianzu's Paired-Assistance, Including 295 Projects. 2018. Available online: http://scnews.newssc.org/system/20180511/000876613.html (accessed on 11 May 2018). (In Chinese)

49. Xinhua Net. Jiangsu and Sichuan Signed Strategic Economic and Social Cooperation Agreements. 2010. Available online: http:/ / news.xinhuanet.com/local/2010-09/15/c_12555029.htm (accessed on 20 December 2013). (In Chinese)

50. Jiangsu News. Jiangsu and Mianzu, We Stand Together, and We a Same Heart and a Common Goal. 2018. Available online: http://jsnews.jschina.com.cn/sxzt/512/mtbd/201804/t20180425_1555274.shtml (accessed on 25 April 2018). (In Chinese)

51. Souhu News. Reborn in Disasters, Significant Changes in Mianzu. 2010. Available online: http://www. sohu.com/a/230757373_212498 (accessed on 20 September 2018). (In Chinese)

52. Mianzu Today. Integrating Local Culture and Tourism, Making the Mianzu become a Famous City. 2018. Available online: http:/ / www.mztoday.gov.cn/show.php?id=29320. (accessed on 6 October 2018). (In Chinese)

53. The State Council of the PRC. Press Conference on Completion of Wenchuan Earthquake Recovery and Reconstruction. 2012. Available online: http://www.scio.gov.cn/xwfbh/xwbfbh/wqfbh/2012/0224/ (accessed on 19 January 2013). (In Chinese)

54. The People's Government of Sichuan Province. Policy for Reinforcement of Seismic Hazard Prevention. 2011. Available online: http:/ /www.sc.gov.cn/10462/10883/11066/2011/12/21/10193912.shtml (accessed on 15 August 2013). (In Chinese)

55. The People's Government of Sichuan Province. Briefing on Wenchuan Earthquakes Disaster Reconstruction and Recovery Process. 2011. Available online: http:/ /www.chinanews.com/gn/2011/10-14/3388830.shtml (accessed on 19 January 2013). (In Chinese)

56. Xinhua Net. 13,000 Potential Hazardous Spots Identified in Areas Affected by Wenchuan Earthquake. 2008. Available online: http://news.xinhuanet.com/newscenter/2008-10/07/content_10161101.htm (accessed on 19 January 2013). (In Chinese)

57. The State Council of the PRC. 35 Projects of Jiangsu and Mianzu Paired-Assistance Are Initiated. 2008. Available online: http:/ / www.gov.cn/jrzg/2008-08/25/content_1078960.htm (accessed on 11 May 2013). (In Chinese)

58. Birkland, T. Lessons of Disasters: Policy Change after Catastrophic Events; Georgetown University Press: Washington, DC, USA, 2006; pp. 173-175, ISBN 158901121X.

59. Quarantelli, E.L. Disaster Recovery: Research Based Observations on What It Means, Success and Failure, Those Assisted and Those Assisting; Preliminary Paper \#263; Disaster Research Center at the University of Delaware: Newark, DE, USA, 1998.

(C) 2018 by the authors. Licensee MDPI, Basel, Switzerland. This article is an open access article distributed under the terms and conditions of the Creative Commons Attribution (CC BY) license (http:/ / creativecommons.org/licenses/by/4.0/). 